\title{
Three Approaches to Ethical Considerations in the Design of Behavior Change Support Systems
}

\author{
Pasi Karppinen, Harri Oinas-Kukkonen \\ Department of Information Processing Science, University of Oulu, Finland \\ pasi.karppinen@oulu.fi, harri.oinas-kukkonen@oulu.fi
}

\begin{abstract}
Many ethical questions arise when developing persuasive systems. It has become evident that there is no silver bullet which would make it easy to resolve all ethical issues in all cases. This paper seeks to analyze and define potential ways to address ethical considerations in persuasive systems design. We suggest that there are three main approaches: a guideline-based approach, stakeholder analysis, and involving users. This paper helps to understand the strengths and weaknesses of these approaches when developing behavior change support systems, which, by their very nature, request deep engagement and commitment from their users. A pragmatic goal for this paper is to help designers choose an approach for their projects at hand.
\end{abstract}

\section{Introduction}

Information technology is never neutral [1]. It influences people's attitudes and behaviors in one way or another, and its developers have to be aware of the full power it exercises over its users [2]. Persuasive and behavior change support systems (BCSS) are designed to create a cognitive and/or emotional change in the mental state of a user [2]. However, due to the many challenges involved, attempting to change users' behaviors or attitudes through these systems can become something of an ethical minefield [3].

The studies of Berdichevsky and Neuenschwander [4] and Fogg [5], [6] were the first academic works to directly address the ethical issues concerning persuasive technology and design. More recently, there has been a growing interest in persuasive ethics, as evidenced by the studies of Burri Gram-Hansen [7], Davis [3], Smids [8], Spahn [9], and Yetim [10]. These studies are convincing pieces of work, but their suggestions for resolving ethical issues differ from one another. Whereas Berdichevsky and Neuenschwander [4] present eight moral principles for the designer to follow, Davis [3] and Yetim [10] argue that designers should find consensus of ethical issues with the stakeholders. Smids [8] concludes that the most important moral question for persuasive technology is the person's voluntariness of change, whereas Spahn [9] sees persuasion as an act of communication, which should always follow validity claims of speech acts. Fogg [5] suggests stakeholder analysis for examining the ethics of com- 
plicated situations, whereas Burri Gram-Hansen [7] introduces ethics as an intuitive result of human nature, rather than as a reason-based rule.

It is hard to argue that any of the abovementioned studies would solely address and help resolve all possible ethical considerations. It is much more fruitful to treat them as potential ways to address different types of ethical challenges. A designer can, of course, build upon lessons learned and academic studies, but it remains open as to how to systematically chooses a suitable ethical approach. The research question for this paper can perhaps be best phrased as: How can we model current approaches in the field of persuasive technology, which address ethical considerations when developing BCSS?

Thus, the goal of this paper is to aid in addressing the ethical considerations in designing persuasive and behavior change support systems. We emphasize the designs of BCSS, as they request deep engagement and commitment from their users, and, thus, many of the ethical questions in them require immediate concern. We propose a conceptual framework, which helps designers choose an approach for the design work at hand; therefore, the contribution of this paper is both pragmatic and academic. We recognize the major categories for approaching ethical considerations, and analyze eight related studies through the framework.

Section 2 will introduce how principles related to BCSS evoke ethical issues that may not be familiar to all persuasive systems. Section 3 concentrates on ethical issues recognized by the Persuasive Systems Design model developed by Oinas-Kukkonen and Harjumaa [1], [11]. In section 4, the framework is introduced. Section 5 discusses how the findings contribute to the actual design work, and examines the strengths and weaknesses of the different approaches.

\section{Ethical considerations recognized by the BCSS approach}

Persuasive technology can be seen as a field of research, whereas a BCSS is an object of study [12]. Oinas-Kukkonen [2] defines BCSS as follows:

A behavior change support system (BCSS) is a socio-technical information system with psychological and behavioral outcomes designed to form, alter or reinforce attitudes, behaviors or an act of complying without using coercion or deception.

As mentioned previously, Smids [8] states that the most important ethical question regarding persuasive technology is the user's voluntariness of change. Smids [8] builds his argument on the demarcation of persuasion, coercion, and manipulation. If BCSS turns out not to rely on voluntary change, it should not be called, sold, or promoted as a persuasive system [8]. BCSS emphasizes autogenous approaches, where a person uses technology to change his/her own behavior or attitude to his/her own goal [2]. Applications that promote healthier lifestyles are typical examples of BCSS. Spahn [9] points out that in self-persuasion, a user already shares the value in question, and uses the persuasive technology only to overcome a 'weakness of the will'. 
He argues that these cases are morally less problematic than using technology to persuade others [9]. Even though the importance of voluntariness seems self-evident, it is not without contradictions, as we will address later.

There are two important steps for measuring behavioral changes: analysis of the persuasion context and analysis of the persuasive potential of the system [2]. For both methods, the $\mathrm{O} / \mathrm{C}$ matrix is used as a means to analyze the intent of a BCSS, and the PSD model is used as a means to analyze the persuasive potential of the system, unveiling a great part of what BCSS are all about [2].

The O/C matrix developed by Oinas-Kukkonen [12] helps to analyze the intent and the outcome of a persuasive system. Successful outcomes in the matrix are the formation, alteration, or reinforcement of attitudes, behaviors, or compliance. A forming outcome (F-Outcome) stands for the birth of a pattern for a situation that did not previously exist. In practice, stopping a behavior also results in a new behavior (FOutcome). An altering outcome (A-Outcome) stands for changes in a user's response to an issue, like increasing exercise. A reinforcing outcome (R-Outcome) stands for the reinforcement of current behaviors or attitudes, which makes them more resistant to change.

In the $\mathrm{O} / \mathrm{C}$ matrix, the changes are also divided into three categories: a change in the act of complying, a behavior change, or an attitude change (C-, B-, and A-Change, respectively). The goal of the $\mathrm{C}$-Change is simply to make sure that the person complies with the system's requests. The goal of a healthcare application can, for instance, guarantee that its user takes his/her daily medication. A system supporting a B-Change aims to elicit a deeper behavior change, rather than mere compliance. A one-off behavior change is naturally easier to achieve, whereas a long-term behavior change is clearly more difficult. The goal of A-Change is to influence a person's attitudes, rather than just their behavior. According to Oinas-Kukkonen [12], change-infull occurs only when attitude change takes place, and a sustainable B-Change happens only through an A-Change.

As reinforcing outcome implies, behavior change does not need to be the transformation from one position to another. The importance of reinforcement is evident when treating addictions, such as smoking or abuse of alcohol. A person 'technically' quits their previous behavior only once, but he/she needs support to continue with the new behavior. Reinforcement is vital, and even though it is no longer a concrete, measurable change in behaviors, support and encouragement are required to keep the end-user's feet on the right path. For another related matter, BCSS can be built on a therapy routine that requires a great deal of compliance from the user. Compliance is not coercion, but, admittedly, it does not fully resonate with the principle of voluntariness either. Spahn [9] sees that technology can be regarded as the implementation of a technological paternalism, which conflicts with the ideal of the free and autonomous choice of the individual. When complying, the person may not have the proper motivation for doing so, and the key becomes to provide triggers for the user to take action and to comply with the requests of the application [2]. Oinas-Kukkonen [2] argues that there are numerous computer applications that use the same design principles and techniques as systems supporting C-Change, and that most research in the area of behavioral change actually focuses on C-Change. 


\section{Ethical considerations recognized by the PSD model}

The Persuasive Systems Design model (PSD) is a vehicle for designing and evaluating BCSS [2]. The PSD model includes the analyses of intent, event, and strategy of persuasion, and also discerns opportune moments for delivering the message(s) [2]. The PSD model defines software features for BCSS that are divided to four categories: primary task support, computer-human dialogue support, perceived system credibility, and social influence [11], [1]. Before analyzing the context or considering persuasive features, the designer should obtain a deeper understanding of persuasion on a postulate level. The seven postulates common to all BCSS [2, cf. 1] are:

(P1) information technology is never neutral, but rather it always influences its user(s) in one way or another;

(P2) people like their views to be organized and consistent;

(P3) persuasion is often incremental;

(P4) the direct and indirect routes are key persuasion strategies;

(P5) BCSS should be both useful and easy to use;

(P6) persuasion through BCSS must always be unobtrusive to a user's primary tasks; and

(P7) persuasion through BCSS should always be transparent.

These postulates have been defined based on both software design and psychology. For instance, as postulate P5 argues, if a system is useless or difficult to use, it is most probably hardly persuasive at all [2]. In this paper, we will focus on postulates regarding the route $(\mathrm{P} 4)$ and transparency $(\mathrm{P} 7)$, as they have very strong implications for the voluntariness principle.

Postulate P4 derives from theories such as the Elaboration Likelihood Model (ELM), and claims that using an indirect route in persuasion is one of the key persuasion strategies [13]. According to ELM, the central route is more enduring, resistant, and predictive of behavior [13], but since people are often too busy with their everyday lives, the indirect route becomes sometimes the only alternative. But, as Spahn [9] argues, persuasion should be based on prior consent. For a person to do things voluntarily, he/she must have clear picture of what he/she is agreeing on [9]. According to Oinas-Kukkonen [2], there may actually also be situations where computermediated persuasion takes place without the user being aware of it. Changing user behavior with the help of subliminal triggers greatly challenges the voluntariness concept. Smids [8] argues that 'unconscious persuasion' is an oxymoron that violates the voluntariness condition, but that lack of awareness on the other hand does not necessarily make persuasive technology manipulative [8], which leaves room for indirect persuasion to be considered ethical as well.

Postulate P7 requires persuasion to be transparent, and underlines the need for revealing the designer's bias behind a BCSS [2]. Atkinson [14] and Davis [3] argue that a user must be informed of the persuaders' intent for persuasion to be ethical. Transparency supports also voluntariness, because it is the only way for users to evaluate if the persuasive system is ethical based on their own moral standards. Berdichevsky 
and Neuenschwander's statement [4], however, reveals one problem concerning transparency:

The creators of a persuasive technology should disclose their motivations, methods, and intended outcomes, except when such disclosure would significantly undermine an otherwise ethical goal.

On the one hand, without transparency users have no choice but to rely on the moral choices the designer has made. On the other hand, if the designer is confident of his/her goals being ethical, why pursue the need for transparency? To some extent, when including the exception for the rule, Berdichevsky and Neuenschwander [4] weaken the role of disclosure, but then also point to the fact that making the methods of persuasion fully transparent may undermine the outcome. Thus, level of openness remains inconclusive in their definition.

As seen above, persuasion is a tricky concept to apply ethical principles to. Atkinson [14] asks that if the user has voluntarily chosen to use a system to achieve a predetermined goal, can we talk about persuasion at all? At the same time, Atkinson [14] refers to Hart's natural right theory, and claims that freedom is an inalienable fundamental human right. This can appear paradoxical at first, but there is a fruitful thought that links together with BCSS. According to Atkinson [14], ethical safeguarding can be achieved if the purpose of the persuasion is exposed at the beginning of one's engagement with a system. Hence, a user can choose whether to accept or reject the BCSS's offering. We see that voluntariness and transparency are important values for persuasive technology, and that the postulates $\mathrm{P} 4$ and $\mathrm{P} 7$ play a big role when a person is engaging with the system. However, we claim that all persuasive acts during the change process do not need to be voluntary or fully transparent.

Oinas-Kukkonen [2] makes the distinction between BCSS and persuasive systems as follows:

A BCSS places more emphasis on the actual outcome than a persuasive system, which, even if its developers were interested in the outcomes as well, in most cases emphasizes more the persuader's intent than measuring the actual outcome.

Behavior change is often a long lasting process that requires commitment and compliance from the user, thus by considering merely the issues of voluntariness and transparency does not mean that the system is automatically on solid ethical ground. In other words, after the user has committed to use the system, this does not give the designer license to do whatever he/she pleases. Some of the BCSS design issues are naturally technical, but many are user-related and social; some may relate to organizations, cultures, or the whole of society [2]. There are a growing number of BCSS that are built jointly with other stakeholders, including end-users [15]. Some aim to improve the wellbeing of entire community. In sum, we see that when designing a BCSS, users and other stakeholders must be taken into account also from an ethical perspective. 


\section{Ethical Framework}

We propose here a conceptual ethical framework, which composes of three categories: guideline-based approaches, stakeholder analysis, and user involvement. The guideline-based category includes ethical approaches that provide general ethical precepts, but do not give explicit guidance on the consideration of users' and other stakeholders' moral norms. The stakeholder analysis category targets ethical approaches that evaluate stakeholders, without actually involving them in the design or the use process. The user involvement category includes approaches that take stakeholders' voices into account in order to seek ethical solutions with them.

We identified seven studies in the persuasive technology research field that focus on ethical issues: Berdichevsky and Neuenschwander [4]; Burri Gram-Hansen [7]; Davis [3]; Fogg [5]; Smids [8]; Spahn [9]; and Yetim [10]. We mapped these works to our ethical framework, and later decided to add Friedman et al.'s [16] study to place more emphasis on the stakeholder analysis category, even though the study does not discuss the persuasive technology field as such. In addition, Davis [3] and Yetim [17] use Friedman et al.'s [16] ideas as a phase for involving users. The abovementioned studies are summarized in Table 1 with their corresponding category and primary ethical contribution from the BCSS design point-of-view.

The guideline-based category contains various approaches, which suggest general principles for addressing ethical issues. As seen also from Table 1, most research interest thus far seems to fall into this category. For example Berdichevsky and Neuenschwander [4] suggest eight principles for persuasive technology and design, which can be summarized as follows: 1) outcomes of persuasion must be considered ethical even without persuasion, or if technology were not involved; 2) motives of the persuader should not be considered unethical when using traditional ways of persuasion; 3 ) designers should take responsibility for all reasonably predictable outcomes of the technology's use; 4) designers must respect the users' privacy as they would respect their own; 5) sharing user's personal information to third parties should be scrutinized for privacy concerns; 6) designers must disclose their motivations, methods, and intended outcomes, except when such disclosure would significantly undermine an otherwise ethical goal; 7) persuasive technology should not misinform the user; and 8) designers should never seek to persuade a user to do something they would not wish to be persuaded to do themselves. The most important guideline is the eighth principle, "the Golden Rule of Persuasion" [2]. Burri Gram-Hansen [7] arrived at the same conclusion, and states that we must strive towards doing to others as we hope others will do unto us. A designer can use the golden rule as a main principle to judge all actions and determine whether any possible action is considered ethical.

The guidelines suggested by Berdichevsky and Neuenschwander [4] are in active use, such as Kaptein and Eckles' [18] recent study on ethical considerations related to persuasion profiling. Berdichevsky and Neuenschwander [4] also specify and emphasize the value of privacy in their guideline, however Kujala and Väänänen-VainioMattila [19] show that values can be retrieved from various different theoretical frameworks, and privacy is just one of many principles. Whether we like it or not, 
guideline-based approaches are fundamentally subjective. What a designer might consider to be ethically correct may be entirely unethical from a user's perspective.

Table 1. Framework of ethical approaches in persuasive technology design.

\begin{tabular}{|c|c|c|}
\hline Approach & Publication & Primary ethical contribution for BCSS designer \\
\hline \multirow[t]{4}{*}{ Guideline } & $\begin{array}{l}\text { Berdichevsky \& } \\
\text { Neuenschwander } \\
{[4]}\end{array}$ & $\begin{array}{l}\text { Eight principles for persuasive technology design, from which } \\
\text { the golden rule is considered most important: The creators of a } \\
\text { persuasive technology should never seek to persuade a person } \\
\text { or persons of something they themselves would not consent to } \\
\text { be persuaded to do. }\end{array}$ \\
\hline & $\begin{array}{l}\text { Burri Gram- } \\
\text { Hansen [7] }\end{array}$ & $\begin{array}{l}\text { Ethical reflections are intuitive and personal. Strive to create a } \\
\text { product that will have impact on the user in a way which } \\
\text { yourself accept as ethically acceptable. }\end{array}$ \\
\hline & Smids $[8]$ & $\begin{array}{l}\text { The most important ethical question regarding persuasive } \\
\text { technology is the person's voluntary desire for change. Do not } \\
\text { use techniques of coercion, manipulation, or subliminal persu- } \\
\text { asion. }\end{array}$ \\
\hline & Spahn [9] & $\begin{array}{l}\text { Three principles for persuasion: } 1 \text { ) persuasion should be based } \\
\text { on prior consent; 2) ideally the aim of persuasion should be } \\
\text { the end of the persuasion; 3) persuasion should grant as much } \\
\text { autonomy as possible to the user. }\end{array}$ \\
\hline \multirow[t]{2}{*}{$\begin{array}{l}\text { Stakeholder } \\
\text { analysis }\end{array}$} & Fogg [5] & $\begin{array}{l}\text { Seven step stakeholder analysis: 1) list all stakeholders; 2) list } \\
\text { what each stakeholder can gain and 3) what they can lose; 4) } \\
\text { evaluate which stakeholder has most to gain and 5) most to } \\
\text { lose; 6) determine ethics by examining gains and losses in } \\
\text { terms of values; 7) acknowledge your own values that you } \\
\text { bring to the analysis. }\end{array}$ \\
\hline & $\begin{array}{l}\text { Friedman et al. } \\
{[16]}\end{array}$ & $\begin{array}{l}\text { Values are retrieved from stakholders through analysis that has } \\
\text { three different layers: conceptual, empirical and technical } \\
\text { investigations. }\end{array}$ \\
\hline \multirow[t]{2}{*}{$\begin{array}{l}\text { User } \\
\text { involvement }\end{array}$} & Davis [3] & $\begin{array}{l}\text { Participation in design. Usage of value-sensitive design to } \\
\text { evaluate the values of the direct and indirect stakeholders, and } \\
\text { participatory design to involve potential users as full partici- } \\
\text { pants in the design process. }\end{array}$ \\
\hline & Yetim [10] & $\begin{array}{l}\text { Conversation in use time. A total of } 21 \text { critical questions that } \\
\text { guide reflections on systems for three discourse types: prag- } \\
\text { matic (goal-value, action-goal, action-value); ethical (identify- } \\
\text { ing, checking); and moral (identifying, checking). }\end{array}$ \\
\hline
\end{tabular}

The stakeholder analysis approach aims to evaluate the values of different stakeholders, and it holds the idea that values vary from one situation to the next, and that there are no easy answers that would satisfy all [5]. The approach is widely used in business ethics [20], [21], and stems from when the traditional shareholder view was con- 
sidered too narrow and ethically insufficient [21]. The stakeholder analysis also aims to consider those groups which do not have the power to make decisions or to participate in decision-making processes, but are nonetheless dependent of the decisions being made [21]. Stakeholder analysis does not mean that suggested ethical guidelines have no meaning. For instance, Fleischman and Wallace [22] argue that transparency is an essential tool to empower and preserve users' autonomy, also from the multiactor viewpoint.

In the persuasive technology field, Fogg [5] identifies seven steps for stakeholder analysis (see Table 1), and argues that the key is for persuasive technology designers to become aware of the range of ethical issues involved. The Value Sensitive Design (VSD) methodology by Friedman, Kahn and Borning [16] is considered the most comprehensive framework for advancing value-centered research [17]. They introduce ten steps for conducting VSD, wherein the key element is the stakeholder analysis [16]. According to Davis [3], the approach emphasizes values of moral import, and thus speaks to ethical concerns surrounding technology design; it also reveals situations in which designers must make tradeoffs between conflicting values, perhaps based on interviews to collect stakeholders' values [16]. Even if stakeholder analysis by no means implies that the designer should remain isolated behind the office desk, it does not really involve users in the design process.

When stakeholder analysis considers stakeholders as the object of study, user involvement approaches seek ethical solutions in terms of these stakeholders. Davis [3] and Yetim [10] have carried out compelling studies on the suggested framework's user involvement category. In fact, their approaches are so different it would be possible to split this category into two streams: participation in design and conversation in use time. Davis [3] uses the VSD [16] method to identify the values of both direct and indirect stakeholders, and takes one step further to engage stakeholders as equal participants in design. When Davis [3] leans on the principles of participatory design, she aims to draw more attention to the welfare of indirect stakeholders, as these people not only use the technology, but are also affected by its use. In her later study, Davis [23] introduces the Inspirational Card Workshop as a method to address ethical issues in participatory design.

To address multiple voices of different stakeholders, Yetim [10] uses Jürgen Habermas' discourse ethics, where the decisive power is given to the most compelling argument. He also underlines that the method is valid also in terms of use time, and not merely in design [17], [10]. In discourse ethics, every stakeholder must be equal in order to participate in the discussion, and instead of settling for a midpoint compromise the agreement should be based on the jointly agreed best argument [24]. Every stakeholder's voice is to be taken seriously, and since the decisive power is given to the most compelling argument [24], Yetim [10] proposes in his study a hierarchy of critical questions that helps identify and decide on ethical arguments during the debate.

Thus far, few published studies on persuasive technology deal with ethical issues. New ethical approaches will be published eventually, and we believe that scholars and designers will be able to map them accordingly to the presented categories in our framework. 


\section{Discussion}

We began this study by claiming that information technology is never neutral. It is indeed constantly affecting our lives. The internet, for example, continues to change businesses, software design, the way we perceive people, and the skills required of us [25]. More specifically, this paper presented a framework for recognizing and choosing suitable ethical approaches for persuasive systems design tasks at hand. In this, voluntariness and transparency were found to be important values.

To make a system as ethically safe as possible along the way, it seems tempting for designers to involve stakeholders in the design process to build ethical consensus through participation and/or conversation. Ethical approaches in the user involvement category are especially useful when the designed system is targeted at a specific and predefined group, i.e. when the goal of conversation can be specific enough, or when building a system jointly with equal partners. However, designers often have only limited resources to do such thorough work in reality.

The user involvement category has two handicaps that designers must take into account. Firstly, building consensus on key values does not make the system automatically ethical. Even though moral values should be emphasized, other values should not be neglected [16]. For instance, monetary wealth is a value too, and some stakeholders may be very keen to have it as a primary goal for the system, whereas others would hold the totally opposite view. Secondly, identifying in addition to direct also indirect stakeholders can be an extremely challenging task. Local solutions can be considered in a broader context, and they can be lifted even to a global scale when thinking about the consumption of natural resources, for instance. The question is when and where to stop the identifying process. Thirdly, designers should also keep in mind that users in most cases do not explicitly think about their values, and can have problems to articulate them, especially when these values are unconscious or perhaps socially unacceptable.

Reaching consensus itself is often hard, and in large software development projects this may be an overly optimistic goal. Developers in responsible positions should be prepared to solve stalemates in such a way that the solution remains ethically solid. Yetim's [10] hierarchies can be fruitful for these types of situations. Mingers and Walsham [24] argue that even the famous open source development project of Linux kernel cannot meet the ideal conditions of discourse ethics, when the inner core of developers have strong rights to control the implementation of changes. This means that contributors are not equally participating in the debate. This type of situation is very common in information systems development practice, where developers are the gatekeepers who make the final decisions on the technical solutions implemented.

Whether the design project is big or small, in order to design BCSS properly, users must be taken into account in multiple stages of design. Practically all systems are built for some target group in mind, and it is only practical to make ethical considerations along the way. If the designer has difficulties imagining himself/herself in someone else's shoes, he/she can interview stakeholders who will be involved with the system. Stakeholder analysis does not demand an overwhelming amount of work, and there are methods such as the Value Senstitive Design that help to identify users' 
values; Kujala and Väänänen-Vainio-Mattila even describe the potential varieties of values, which makes identifying values easier [19]. Stakeholder analysis seems to be a particularly suitable approach for situations where the use context of the system [cf. $15]$ is clear, as value-based product solutions often are highly context-dependent [19]. Stakeholder analysis is suitable also to identify values, but similarly to user involvements it says nothing about the norms stakeholders should follow [21]. It seems to be that in the field of persuasive technology, the stakeholder analysis category is yet to receive more of the rigorous scientific investigation. Nevertheless, it may turn out to be a very useful method to aid design.

In the current business climate, it is very easy to launch a BCSS to global markets, which makes the identification of stakeholders and analyzing their values ever more important, despite the fact that this is a time-consuming and wearisome task. Guidelines may operate as checklists to tackle important ethical issues. As a definition, BCSS do not deceive, manipulate, or coerce users; they should be transparent to enable an individual's free choice to engage with the system [2]. Users rely on BCSS developers as experts of their topic, and expect the system to deliver what it promises. However, if the system is badly designed and a user does not have a chance to achieve his/her goal for this reason, it can be considered unethical as well. Professionals often regard ethics as a source of edification, and fail to realize that they encounter ethical issues and challenges in the ordinary course of their work [26]. However, questions of appropriate actions can arise partly in situations where nobody has done anything clearly wrong [26].

In overall, BCSS are deliberately designed to change users' behavior, and, as Berdichevsky and Neuenschwander stated [4], we as designers ought to take responsibility for the outcomes of a system's use that are reasonably predictable. However, it remains practically impossible for designers to predict all outcomes for all stakeholders, based on their own limited perspectives [3], and no experimental approaches have the ability to solve all questions of morality and ethics when designing BCSS. Thus, the designers should choose a suitable approach for the task at hand based on an awareness of their values and the values which will be brought into the design. Better yet, values should be explicitly specified and exemplified. At times, a designer faces a situation where he/she has no other option, but to simply count on his/her own reasoning or perhaps even intuition. Being faithful to one's intuition is not naïve nonsense [cf. 7]. If you feel that what you are doing is unethical - just do not do it.

\section{Conclusion}

The motivation for this study rises from the important goal to support ethical design of persuasive and behavior change support systems. Due to the lack of a single approach that could be used in all design cases, designers need conceptual help to choose a suitable approach for the design case at hand. By using the BCSS design principles [2] and the PSD design model [1], it was possible to recognize the major ethical approaches, differentiate how they deal with issues related to users and other stakeholders, and propose a conceptual framework to help persuasive designers and 
researchers. The ethical framework comprises three major categories: guideline-based approaches, stakeholder analysis, and user involvement. The framework is unique for persuasive technology and design, and a special characteristic is that it is built from the design perspective, rather than from philosophical traditions, focusing on the practical need to solve ethical questions in the design. Moreover, philosophically oriented researchers may benefit from this framework by being able to recognize areas in which designers urgently need ethical guidance. In the proposed framework, the values of voluntariness and transparency play a vital role for a user to be able to decide whether to commit to the use of a BCSS. However, even they, or other guidelines, do not guarantee a system's high ethical status.

In conclusion, the current base of knowledge is still very limited for addressing ethical considerations in the field of persuasive technology. There is a need for more studies regarding the ethical design and development of persuasive and BCSS. The evidence for the proposed framework is also limited. Thus, we invite designers and researchers to put the framework into practice, to scrutinize it under evaluation, and to report their lessons learned.

Acknowledgements. We wish to thank the anonymous reviewers of this paper for their insightful comments. The study was partially supported by the SalWe Research Program for Mind and Body, grant 1104/10, and the Someletti research project on Social Media in Public Space, grant 1362/31, both provided by Tekes, the Finnish Funding Agency for Technology and Innovation.

\section{References}

1. Oinas-Kukkonen, H., Harjumaa, M.: Persuasive Systems Design: Key Issues, Process Model, and System Features. Communications of the Association for Information Systems, 24, 485-500 (2009)

2. Oinas-Kukkonen, H.: A Foundation for the Study of Behavior Change Support Systems. Personal and Ubiquitous Computing, 1-13 (2012)

3. Davis, J.: Design Methods for Ethical Persuasive Computing. In: 4th International Conference on Persuasive Technology, pp. 1-8. ACM, NY (2009)Berdichevsky, D., Neuenschwander, E.: Toward an Ethics of Persuasive Technology. Communications of the ACM. 42, 51-58 (1999)

4. Fogg, B. J.: Persuasive technology: Using computers to change what we think and do. Morgan Kaufman, San Francisco (2003)

5. Fogg, B. J.: Persuasive Computers: Perspectives and Research Directions. In: Proceedings of the SIGCHI Conference on Human Factors in Computing Systems, pp. 225-232. ACM, NY (1998)

6. Gram-Hansen, S. B.: Towards an Approach to Ethics and HCI Development Based on Logstrup's Ideas. In: Gross, T., Gulliksen, J., Kotzé, P., Oestreicher, L., Palanque, P., Prates, R.O., Winckler, M. (eds.) Human-Computer Interaction - INTERACT 2009, vol. 5726, pp. 200-203. Springer, Heidelberg (2009)

7. Smids, J.: The Voluntariness of Persuasive Technology. In: Bang, M., Ragnemalm, E. (eds.) Persuasive Technology. Design for Health and Safety. LNCS, vol. 7284, pp. 123-132. Springer, Heidelberg (2012) 
8. Spahn, A.: And Lead Us (Not) into Persuasion...? Persuasive Technology and the Ethics of Communication. Science and Engineering Ethics. 18, 1-18 (2011)

9. Yetim, F.: A Set of Critical Heuristics for Value Sensitive Designers and Users of Persuasive Systems. In: ECIS 2011 Proceedings. Helsinki (2011)

10. Oinas-Kukkonen, H., Harjumaa, M.: A Systematic Framework for Designing and Evaluating Persuasive Systems. In: Oinas-Kukkonen, H., Hasle, P., Harjumaa, M., Segerståhl, K., Øhrstrøm P. (eds.) Persuasive Technology. LNCS, vol. 5033, pp. 164-176 (2008)

11. Oinas-Kukkonen, H.: Behavior Change Support Systems: A Research Model and Agenda. In: Ploug, T., Hasle, P., Oinas-Kukkonen, H. (eds.) Persuasive Technology. LNCS, vol. 6137, pp. 4-14 (2010)

12. Petty, R. E., Cacioppo, J. T.: Communication and Persuasion: Central and Peripheral Routes to Attitude Change. Springer, New York (1986)

13. Atkinson, B. M. C.: Captology: A Critical Review. In: IJsselsteijn, W.A., de Kort, Y.A.W., Midden, C., Eggen, B., van den Hoven, E (eds.) Persuasive Technology . LNCS, vol. 3962 171-182 (2006)Ahola, H., Oinas-Kukkonen, H., Koivumaki, T.: Customer Delivered Value in a Web-Based Supermarket. In: Proceedings of the 33rd Hawaii International Conference on Systems Sciences (HICSS '2000). IEEE Computer Society Press (2000)

14. Friedman, B., Kahn Jr, P. H., Borning, A.: Value Sensitive Design and Information Systems. In: Zhang, P. and Galletta, D. (eds.) Human-Computer Interaction and Management Information Systems: Foundations, pp. 348-372. M.E. Sharpe, New York (2006)

15. Yetim, F.: Bringing Discourse Ethics to Value Sensitive Design: Pathways to Toward a Deliberative Future. AIS Transactions on Human-Computer Interaction. 3, 133-155 (2011)

16. Kaptein, M., Eckles, D.: Selecting Effective Means to any End: Futures and Ethics of Persuasion Profiling. In: Ploug, T., Hasle, P., Oinas-Kukkonen, H. (eds.) Persuasive Technology. LNCS, vol. 6137, pp. 82-93 (2010)

17. Kujala, S., Väänänen-Vainio-Mattila, K.: Value of Information Systems and Products: Understanding the Users' Perspective and Values. Journal of Information Technology Theory and Application. 9, 23-39 (2009)

18. Goodpaster, K. E.: Business Ethics and Stakeholder Analysis. Business Ethics Quarterly. 1, 53-73 (1991)

19. Stahl, B. C.: Ethical Issues of Information and Business. In: Himma, K.E. and Tavani, H.T. (eds.) The Handbook of Information and Computer Ethics, pp. 311-359. John Wiley \& Sons, Hoboken (2008)

20. Fleischmann, K. R., Wallace, W. A.: A Covenant with Transparency: Opening the Black Box of Models. Communications of the ACM. 48, 93-97 (2005)

21. Davis, J.: Generating Directions for Persuasive Technology Design with the Inspiration Card Workshop. In: Ploug, T., Hasle, P., Oinas-Kukkonen, H. (eds.) Persuasive Technology. LNCS, vol. 6137, pp. 262-273 (2010)

22. Mingers, J., Walsham, G.: Toward Ethical Information Systems: The Contribution of Discourse Ethics. MIS Quarterly. 34, 833-854 (2010)

23. Oinas-Kukkonen, H., \& Oinas-Kukkonen, H.: Humanizing the web: Change and social innovation. Palmgrave Macmillan, Basingstoke, UK (2013)

24. Goodman, K. W.: Health Information Technology: Challenges in Ethics, Science, and Uncertainty. In: Himma, K.E. and Tavani, H.T. (eds.) The Hand-book of Information and Computer Ethics, pp. 293-309. John Wiley \& Sons, Hoboken (2008) 